\title{
Future direction for the CSCL field: Methodologies and eight controversies
}

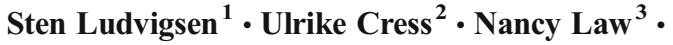 \\ Gerry Stahl ${ }^{4} \cdot$ Carolyn P. Rosé $^{5}$
}

Published online: 5 December 2017

(C) International Society of the Learning Sciences, Inc. 2017

\section{Introduction}

This issue presents three award-winning contributions from the CSCL 2017 conference recently held in Philadelphia. This journal invited the authors of the three papers to rewrite and extend their papers for full journal publication. The submitted papers have undergone several phases of peer review, in addition to the original review for the conference. By inviting the award-winners to further publish their excellent work in the journal, we hope to extend the reach of these new voices and approaches to the broader CSCL and learning sciences community. The following sections provide further information about the three papers. The fourth paper represents a novel genre in CSCL. The current research community

Sten Ludvigsen

Sten@ijCSCL.org

Ulrike Cress

Ulrike@ijCSCL.org

Nancy Law

Nancy@ijCSCL.org

Gerry Stahl

Gerry@ijCSCL.org

Carolyn P. Rosé

cprose@cs.cmu.edu

1 University of Oslo, Oslo, Norway

2 Knowledge Media Research Center, Tübingen, Germany

3 University of Hong Kong, Hong Kong, China

4 Drexel University, Philadelphia, PA, USA

5 Carnegie Mellon University Language Technologies Institute and HCI Institute, Gates-Hillman Center 5415, 5000 Forbes Ave, Pittsburgh, PA 15213-3891, USA 
uses several meta-approaches, such as meta-analysis, systematic reviews, conceptual reviews, and so on. The former president of the International Society of the Learning Sciences, Carolyn P. Rosé, initiated a process where Alyssa Wise and Baruch Schwarz were asked to conduct a study on the history, status, and future of CSCL. The fourth paper presents the results of the review and exploration of the field.

\section{New methodologies/methods of analyzing collaborative learning}

In CSCL, different research methods contribute to our understanding of the phenomena that we study. Today, new methods are emerging, such as automatic analysis (forms of learning analytics) (Berland et al. 2015) and new ways of connecting actions, conversations, and gestures that form part of participants' meaning-making processes. Interaction analysis (Jordan and Henderson 1995) has been an important methodology for many CSCL researchers over the last 20 years (Furberg 2016), which has been extended with the inclusion of gestures and the body (Davidsen and Ryberg 2017; Enyedy et al. 2015). In their paper, Ben Rydal Shapiro, Rogers P. Hall, and David A. Owens extend the focus by including physical movements in their analysis.

Their study was performed in a cultural heritage museum, based on the data collected from 22 groups. The groups had diverse backgrounds; some of them were professionals in a particular domain (music). The rich data set provides information about the participants' (visitors') movements and talk in the museum setting, across different forms of representations, photographs, videos, descriptions, and online conversations about their experiences.

Museums are settings where the integrated designs of the physical and the symbolic environments create a set of affordances for the visitors. Through movement analysis, researchers can explore how the syntax of space creates an "interaction geography" from which visitors' gestures and activities can be analyzed. The authors connect novel forms of analyses to constitute the key elements of the analytical approach that they named as interaction geography.

The authors argue they their study should be seen as the first step in exploring the use of interaction geography. Further studies using this analytic technique in a variety of settings would be necessary to explore the potential contribution that this line of inquiry can bring to the CSCL community. In addition to the analysis by the authors, temporal analysis would also be useful since participation can change over time and this will have implications for redesign. Ethical concerns should also be discussed when collecting data with small cameras, such as those worn on a necklace. As researchers, we often need detailed data, while ensuring that the tools we use do not become too intrusive for the participants.

\section{Dialogues in museums: New methods that support talk in open-ended queries}

The study of dialogue is one of the most frequent approaches employed to understand participants' actions in CSCL settings (Stahl 2015). Dialogues can be examined in different ways, including conversation analysis, interaction analysis, and positioning theory (Arnseth and Krange 2016; Stahl 2015; Harré et al. 2009). In their paper, Jessica Roberts and Leilah Lyons present a new method called Scoring Qualitative Informal Learning Dialogues (SQUILD), 
which aims to measure informal talk and learning in open-ended museum settings. More precisely, this tool can be used to quantify social learning as a way of testing how participants understand interactive exhibits. The paper's central concept involves full-body interactive experiences, including social, emotional, and cognitive aspects of the learning process.

As an important part of the interactive design, the Co-Census software captures data about visitors' identities and some aspects of their lives (family and work), based on a few questions. The idea is that the personalized data should spark more interest and increase the quality of the dialogues that are performed during the museum visit (in this case, the experiment). The method used in the study is an experimental design. Using the Co-Census interactive design makes it possible for the participants to control the visualization produced by their bodily movements and to interact with other participants.

The paper seeks to address three challenges: (1) identifying open-ended learning with interactive exhibits, which means developing relevant codes; (2) segmenting a dialogue to permit cross-group comparisons, which is concerned about how to define an appropriate unit of analysis and an adequate level of description (in this case, the event unit); and (3) respecting socially constructed learning when quantifying dialogue, which entails addressing the depths of and nuances in the visitors' performances and talks.

How does SQuILD work to address the mentioned challenges? Roberts and Lyons modestly acknowledge that the method has some weaknesses that need further improvements, such as more in-depth work on the process aspects of bodily movement and their relationship with talk. Some aspects can be controlled in laboratory settings, but it is difficult to control processes in situ in a museum. However, the method should be regarded as a step forward that can support the more nuanced analysis of collaborative learning and cross-comparisons of groups in open-ended settings.

\section{CSCL designs: Proximity in interpersonal relations and self-efficacy}

Interpersonal closeness and peer tutoring should be regarded as core issues in CSCL since instruction and collaboration in multiple settings are the aspects investigated by the field (e.g., Järvelä et al. 2016; Ludvigsen and Arnseth 2017). However, IJCSCL has rarely published papers on these issues in the past.

In face-to-face interaction in most cultures, the issue of maintaining other people's good impression of a person's mastery of the situation is important. In a learning setting, what would typically be construed as a face-threatening action can instead be considered a natural part of an activity. In many research fields in the social sciences, face-threatening, politeness, and trust can be perceived as classical themes (Brown and Levinson 1987; Goffman 1967). In Michael Madaio, Justine Casell, and Amy Ogan's paper, issues related to interpersonal closeness and peer tutoring are investigated. These dimensions are explored in instructional tasks. In interpersonal relationships, the functions of directness and indirectness are important. In different settings, directness/indirectness can be played out with certain variations. When difficulties are experienced, most people would increase their sensitivity about what to say and how to formulate and express it. Communication can often be viewed as subtle phenomenon. As we know in CSCL, collaboration in instructional tasks is a complex issue, as is the collaboration between tutor and tutee.

Madaio, Casell, and Ogan's paper is based on an experiment with 12 dyads who work in the domain of linear algebra. The students involved were randomly assigned to the role of either 
tutor or tutee. The study's participants worked in five sessions, each lasting one hour per week, with a total corpus of $60 \mathrm{~h}$. The results show that in interpersonal relationships self-efficacy matters. The tutors with greater self-efficacy perform better in achieving interpersonal and instructional goals. As tutors, they engage more in the subtleties of the interaction, in which direct instruction and indirectness are crucial. Tutors with lower self-efficacy seem to show greater avoidance of mitigating face-threatening tactics. These results pose important challenges to CSCL design, such as which aspects of the social dynamics we can actually design for (Tchounikine 2016).

\section{CSCL: History, status, and future direction or eight provocations for the CSCL field}

Wise and Schwarz's paper is written in the form of an argumentative dialogue between a provocateur and a conciliator, which does not represent a conventional genre in this journal, but we think that this is an innovative and original contribution to the CSCL field. Their initial approach was to examine review studies that created premises for the interviews with experts in the field. Another source of premises was their own work in the field for at least 15 years, by publishing papers in the CSCL proceedings and in this journal, as well as being active in the community's conferences and committees.

Based on their overview and synthesis of written interviews with CSCL experts, they distilled eight controversies in the field. These controversies are presented as conversations between a provocateur/provocatrice and a conciliator. The conversations could be viewed as narrative reviews of the field. The provocations are entitled as follows: 1) The blossoming of CSCL tools necessitates "one framework to rule them all." 2) Prioritize learner agency over collaborative scripting. 3) Collaboration and community should be scrutinized scrupulously rather than adhered to as a matter of ideology. 4) The co-habitation of analytical and interpretive approaches in CSCL is actually a situation of co-alienation that cannot be surmounted. 5) Vigorously pursue computational approaches to understanding collaborative learning. 6) Learning analytics and adaptive support should be priorities for CSCL. 7) Evolve or become irrelevant. 8) CSCL should give up on educational change.

In the argumentation between the provocateur and the conciliator, foundational problems in CSCL are at stake, such as how we conceptualize the relationship between computational artefacts and the collaboration they support. Other issues are raised by questions like: How can we understand or predict the nature of the mediation between humans and designed artefacts? What are the most appropriate units of analysis and levels of descriptions for CSCL studies? Should we use one unified theoretical stance, or are the multiple stances currently used more productive for our field?

The contents of these provocations and the pros and cons of the positions debated offer the field new and stimulating aspects to consider.

\section{Conclusion}

This issue presents two studies that emphasize methodological aspects and new analytic techniques in the field. Designing for learning in museums seems to be a growing area in CSCL. We think that as a special venue for collaborative learning it enriches CSCL research, 
and we hope that additional novel and high-quality museum studies will be published in the years to come. The paper that brings in interpersonal relationship and self-efficacy opens a new perspective on CSCL. Although the ideas of politeness and face-threatening are classical themes in the social sciences, the paper combines these themes and CSCL research in an innovative way.

The review paper with the eight controversies should provoke the CSCL community for years to come. We hope that we will receive both original contributions and a number of squibs that express critical concerns about Wise and Schwarz's paper or elaborate positions and raise new controversies.

\section{References}

Arnseth, H. C., \& Krange, I. (2016). What happens when you push the button? Analyzing the functional dynamics of concept development in computer supported science inquiry. International Journal of Computer-Supported Collaborative Learning, 11(4), 479-502.

Berland, M., Davis, D., \& Smith, C. P. (2015). AMOEBA: Designing for collaboration in computer science classrooms through live learning analytics. International Journal of Computer-Supported Collaborative Learning, 10(4), 425-447.

Brown, P., \& Levinson, S. C. (1987). Politeness: Some universals in language use. Cambridge: Cambridge University Press.

Davidsen, J., \& Ryberg, T. (2017). "This is the size of one meter": Children's bodily-material collaboration. International Journal of Computer-Supported Collaborative Learning, 12(1), 65-90.

Enyedy, N., Danish, J. A., \& De Liema, D. (2015). Constructing liminal blends in a collaborative augmentedreality learning environment. International Journal of Computer-Supported Collaborative Learning, 10(1), $7-34$.

Furberg, A. (2016). Teacher support in computer-supported lab work: Bridging the gap between lab experiments and students' conceptual understanding. International Journal of Computer-Supported Collaborative Learning, 11(1), 89-113.

Goffman, E. (1967). Interaction ritual: Essays on face-to-face behavior. New York: Anchor Books.

Harré, R., Moghaddam, F. M., Cairnie, T. P., Rothbart, D., \& Sabat, S. (2009). Recent advances in positioning theory. Theory \& Psychology, 19(1), 5-31.

Järvelä, S., Kirschner, P. A., Hadwin, A., Järvenoja, H., Malmerg, J., Miller, M., \& Laru, J. (2016). Socially shared regulation of learning in CSCL: Understanding and prompting individual- and group-level shared regulatory activities. International Journal of Computer-Supported Collaborative Learning, 11(3), 263-280.

Jordan, B., \& Henderson, K. (1995). Interaction analysis: Foundations and practice. The Journal of the Learning Sciences, 4(1), 39-103.

Ludvigsen, S., \& Arnseth, H. A. (2017). Computer-supported collaborative learning. In E. Duval, M. Sharples, \& R. Sutherland (Eds.), Technology enhanced learning (pp. 47-58). Cham: Springer International.

Stahl, G. (2015). A decade of CSCL. International Journal of Computer-Supported Collaborative Learning, 10(4), 337-344.

Tchounikine, P. (2016). Contribution to a theory of CSCL scripts: Taking into account the appropriation of scripts by learners. International Journal of Computer-Supported Collaborative Learning, 11(3), 349-369. 